\title{
UPLCMS Method Development and Validation of Tablet Dosage form Containing Glimepiride, Metformin and Pioglitazone Using Internal Standard
}

\author{
${ }^{1}$ Anandkumar R. Tengli, ${ }^{2,}$ Shivakumar G \& ${ }^{3,}$ Gurupadayya B. M.

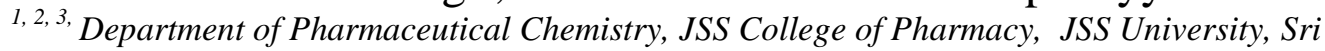 \\ Shivarathreeshwara Nagar, Mysore-570015, India;
}

\begin{abstract}
A simple, rapid, sensitive and specific Ultra performance liquid chromatography-tandem mass spectrometry method was developed and validated for simultaneous estimation and validation of tablet dosage form containing glimepiride (GLIM), metformin (MET) and pioglitazone (PIO) using Tolzamide (TOLAZ) as an internal standard (IS). The chromatography separation was achieved with Waters ACQUITY HSS C18, $1.8 \mu \mathrm{m}$, $2.1 X 50 \mathrm{~mm}$ column with mobile phase containing acetonitrile (A) \& 1\% ammonium acetate buffer $(B)$ ( $p H 2.5$ adjusted with trifluoro acetic acid) with gradient mode Gradient mode [2 min: 20 A : 80\% B, 2-4 min: 70\% A : $30 \% \mathrm{~B}, 4-5 \mathrm{~min}, 80 \% \mathrm{~A}: 20 \% \mathrm{~B}, 8-10 \mathrm{~min} 90 \% \mathrm{~A}: 10 \% \mathrm{BJ}$. The flow rate was $0.4 \mathrm{~mL} \mathrm{~min}{ }^{-1}$ column maintained at $25^{\circ} \mathrm{C}$ and the injection volume was $2 \mu \mathrm{l}$. The selected chromatographic condition were found to effectively separate glimepiride, metformin and pioglitazone with retention time of 3.17, 0.425, 2.3 min, respectively. The proposed method was found to be rectilinear over the range of 2-12 $\mathrm{ng} \mathrm{mL}^{-1}, 500-3000 \mathrm{ng} \mathrm{mL} L^{-1}$ and 15-90 $\mathrm{ng}$ $m L^{-1}$ for glimepiride, metformin, and pioglitazone respectively. The signal intensities obtained in both positive and negative ion mode all drugs including internal standard found to be much higher in positive ion mode ( $M$ $+H)+$ parent ions at $\mathrm{m} / \mathrm{z}, 491.11, \mathrm{~m} / \mathrm{z} .129 .87, \mathrm{~m} / \mathrm{z} 357.04$ and $\mathrm{m} / \mathrm{z} 312.04$ respectively in QUATTROZQ full scan mass spectra. The present method was validated as per ICH guidelines with respect to precision, specificity, linearity, limit of detection, limit of quantification, accuracy, and robustness and it can also be used for routine quality control analysis of these drugs in biological samples either alone or in combined pharmaceutical dosage forms.
\end{abstract}

Keywords: UPLCMS, glimepiride, metformin, pioglitazone and tolazamide simultaneous estimation

\section{INTRODUCTION}

Diabetes and its abnormalities constitute a major health problem in the modern society [1]. It is characterized by disrupted insulin production, leading to high blood glucose concentration and other complications such as renal dysfunction, neuropathy and cardiopathy [2]. Type II diabetes is a complex metabolic disorder with two major biochemical defects, namely impaired insulin secretion and impaired insulin action at the periphery. Chronic hyperglycemia results from these defects. Many oral antidiabetic drugs with different mechanisms of action have been developed to lower blood sugar and delay the occurrence of serious complications in patients with type II diabetes [2]. For glycemic control in such cases, monotherapy with an oral antidiabetic agent is not adequate to achieve satisfactory blood glucose control [3]. Thus, combination regimens which include drugs with different and complementary mechanisms of action are recommended. The combinational therapy for type II diabetes [4-5] is frequently prescribed when mono therapy fails. The combination of metformin (MET), pioglitazone (PIO), and glimepiride (GLIMP) is approved by FDA for treatment of type II diabetes [6].

Metformin is an orally administered antihyper glycemic drug that lowers glucose by reducing hepatic glucose production and gluconeogenesis and by enhancing peripheral glucose uptake [7].

Pioglitazone is an oral antidiabetic agent used in the treatment of type II diabetes. After administration, pioglitazone decreases insulin resistance in the periphery and liver resulting in increased insulin dependent glucose disposal and decreased hepatic glucose output [8-9]. PIO act through PPAR $\gamma$, a member of the nuclear receptor superfamily of ligand activated transcription factors [7]. Once activated, PPAR $\gamma$ forms a heterodimer with another nuclear receptor, the retinoid-X receptor. This heterodimer then binds to specific DNA sequences and regulates the transcriptional activity of target genes that play a role in the metabolism of glucose and lipids [7-9]. Glimepiride is an oral sulfonylurea hypoglycemic agent indicated for the treatment of type II diabetes mellitus. The sulfonylurea glimepiride used widely in the treatment of noninsulin dependent Type II diabetes mellitus [10]. It acts by stimulating insulin secretions from the beta cells of pancreas and is also known to increase peripheral insulin sensitivity thereby decreasing insulin resistance. 
As per the literature, various methods are available for the estimation of these three drugs individually or in combination of two drugs in a pharmaceutical dosage form and also from biological samples. Very few methods are available for simultaneous estimation of all the three drugs together in a tablet dosage form [10] This paper describes a simple, precise, and accurate UPLCMS method for simultaneous estimation of metformin, glimepiride and pioglitazone.<smiles>CN(C)C(=N)NC(=N)[Hg]</smiles>

Metformin<smiles>CCOc1ccc(CCOc2ccc(CC3SC(=O)NC3=O)cc2)cn1</smiles><smiles>CCCC1=C(C)CN(C(=O)NCCc2ccc(S(=O)(=O)NC(=O)NC3CCC(C)CC3)cc2)C1=O</smiles>

\section{2. a. Materials and reagents}

\section{EXPERIMENTAL}

Working standards, Glimepiride (GLIMP), Metformin (MET) and Pioglitazone (PIO) were procured from Ranbaxy laboratories, New Delhi, India. Ammonium acetate AR grade, HPLC grade Acetonitril, Methanol and water from Ranchem, Mumbai. The pharmaceutical dosage form containing GLIMP 2 mg, MET 500 mg \& PIO 15 mg Geoglit GM (Cadila pharmaceuticals Ltd.), 20 tablets purchased from a local drug store. Tolazamide which was employed as an internal standard (IS) was obtained from Ranbaxy Laboratories, New Delhi.

\section{Instrumentation}

\section{UPLC Condition}

The development and validation of the assay was performed on a Waters Aquity UPLC Micromass Quattro Micro API Mass spectrometer (Waters Corp., MS, USA), equipped with a binary solvent delivery system, auto sampler, photodiode array and ELSD detector. The chromatography was performed on a 
ACQUITY HSS C18, $1.8 \mu \mathrm{m}, 2.1$ X50 column (Waters Corp., Ireland) with mobile phase containing acetonitrile (A) \& $1 \%$ ammonium acetate (B) buffer $\mathrm{pH} 2.5$ adjusted with trifluoro acetic acid, [Gradient mode (2 min: 20 A : $80 \%$ B, $2-4$ min: $70 \%$ A : $30 \%$ B, $4-5 \min , 80 \%$ A : $20 \%$ B, $8-10 \min 90 \%$ A: $10 \%$ B)]. The flow rate was $0.4 \mathrm{~mL} \mathrm{~min}{ }^{-1}$ column maintained at $25^{\circ} \mathrm{C}$ and the injection volume was $2 \mu \mathrm{l}$.

\section{MS Condition:}

Ion polarity: ES+, Ion source type: Atmospheric Pressure Electrospray Ionisation, Capillary voltage $(\mathrm{kv})$ : 3.50-3.51, Cone voltage(v): 30.00-33.09, Source temperature $\left({ }^{\circ} \mathrm{c}\right): 120-119$, Desolvation gas flow $(1 / \mathrm{h})$ : 1000-998, Cone gas flow (L/Hr): 50-50, Desolvation gas temperature $\left({ }^{\circ} \mathrm{c}\right): 500-498$, A mass spectrum was over a scan range of $m / z$ : 50 Da to 2048 Da, Extractor: 3.00-3.79, Ion Energy: 1-0.5.

\section{Standard Preparation}

Separate stock solutions of $10,000 \mathrm{ng} \mathrm{mL}^{-1}$ of glimepiride, metformin, pioglitazone and tolazamide were prepared by dissolving in $25 \mathrm{~mL}$ HPLC grade Methanol and diluted to $100 \mathrm{~mL}$ with acetonitrile, then 10 $\mathrm{mL}$ of stock solution into a $100 \mathrm{~mL}$ of standard volumetric flask and diluted with acetonitrile (stock solution contains $1000 \mathrm{ng} \mathrm{mL}^{-1}$ ). The prepared stock solutions were stored at $25^{0} \mathrm{C}$ protected from light.

\section{Preparation of Calibration Plot}

Standard solutions were freshly prepared from the stock solution by diluting with acetonitrile as $2,4,6$, $8,10 \& 12 \mathrm{ng} \mathrm{mL}^{-1}$ glimepiride, 500, 1000, 1500, 2000, $2500 \& 3000 \mathrm{ng} \mathrm{mL}^{-1}$ of metformin and 15, 30, 45, 60, $75 \& 90 \mathrm{ng} \mathrm{mL}^{-1}$ pioglitazone respectively. Each solution was injected in triplicate and chromatographed under the chromatographic conditions specified above. Tolazamide $\left(20 \mathrm{ng} \mathrm{mL}^{-1}\right)$ was used as internal standard for determination of mixtures of glimepiride, metformin \& pioglitazone with tolazamide. Linear relationships were obtained when drug to internal standard peak-area ratios were plotted against the corresponding concentrations for each drug.

\section{Sample Preparation}

Average weight was calculated by weighing 20 tablets. The tablets were crushed into homogenous powder. A quantity of powder equivalent to one tablet containing $2 \mathrm{mg}$ of glimepiride, $500 \mathrm{mg}$ of metformin and $15 \mathrm{mg}$ of pioglitazone was transferred into a $100 \mathrm{~mL}$ volumetric flask. To this flask, $25 \mathrm{~mL}$ of methanol were added, and the solution was sonicated for $30 \mathrm{~min}$ with intermittent shaking. The solution was cooled to ambient temperature. Then the volume was made up with acetonitrile and centrifuged at 10,000 rpm for $10 \mathrm{~min}$. The centrifuged solution filtered through a $0.45 \mu \mathrm{m}$ Nylon filters (Millipore, Milford, MA, USA). From the filtered solution, aliquots of appropriate volume were transferred to $10 \mathrm{~mL}$ volumetric flasks and diluted to volume with acetonitrile to furnish the concentration range listed in Table - $\mathbf{1}$.

\section{Method Validation}

\section{* Linearity \& Range}

The linearity of the method was evaluated by analyzing different concentration of the drugs. According to $\mathrm{ICH}$ recommendations, at least five concentrations must be used. In this study six concentrations were chosen, in the ranges $2,4,6,8,10 \& 12 \mathrm{ng} \mathrm{mL}^{-1}$ glimepiride, 500, 1000, 1500, 2000, $2500 \& 3000 \mathrm{ng} \mathrm{mL}^{-1} \mathrm{of}^{-}$ metformin and $15,30,45,60,75 \& 90 \mathrm{ng} \mathrm{mL}^{-1}$ pioglitazone respectively.

\section{* Accuracy and precision}

The accuracy of the method was determined by recovery experiments using the standard addition method. Each solution was injected in triplicate and percentage recovery was calculated. The precision of the method was assessed by studying intra-day and inter-day variation. In the intra-day studies, standard and sample solutions were analysed in triplicate on the same day and percentage RSD was calculated. In the inter-day studies, standard and sample solutions were analysed in triplicate on three consecutive days and percentage RSD were calculated.

\section{* Limits of Detection (LOD) and Limit of Quantitation (LOQ)}

In accordance with ICH recommendations the approach based on the standard deviation of the response and the slope of the calibration plots was used to determine detection and quantification limits. LOD and LOQ values were estimated as [(standard deviation of repeatability)/(Slope of the regression equation)] by multiplying with 3.3 and 10 respectively. The values obtained are given in Table -4. 


\section{* Selectivity}

The selectivity of the method was evaluated by assessing whether excipients present in the pharmaceutical formulations interfered with the analysis. A placebo for each tablet was prepared by mixing the respective excipients, and solutions were prepared by following the procedure described in the section on sample preparation. The commonly used tablet excipients did not interfere with the method.

\section{* Robustness}

Robustness is a measure of capacity of analytical methods to remain unaffected by small but deliberate variation of the operating conditions. This was tested by studying the effect of changing mobile phase $\mathrm{pH}$ by \pm 0.2 , the amount of buffer in the mobile phase by $\pm 2 \%$, and detector wavelength by $\pm 2 \mathrm{~nm}$

\section{RESULTS AND DISCUSSION}

It is important to optimize the UPLC conditions and develop UPLCMS method and validate in pharmaceutical formulations, preliminary tests were performed with the objective of selecting optimum chromatographic conditions. The separation was tried using different columns described previously in the literature or alternative stationary phases. The main problems encountered during these investigations were lack of resolution between glimepiride, metformin and pioglitazone with IS. To solve these problems, three columns, HSS C18, BEH C8, and BEH Phenyl, BEH C18 were used for simultaneous determination of the drugs. The best resolution and peak shape, without excessive tailing, were obtained by use of the HSS C18 column. The effect of mobile phase composition, flow rate and $\mathrm{pH}$ were also studied. The best resolution with reasonable retention time was obtained with mobile phase containing acetonitrile and $1 \%$ ammonium acetate buffer $\mathrm{pH}$ adjusted 2.5 with trifluoroacetic acid in gradient elution mode with $0.5 \mathrm{~mL} \mathrm{~min}^{-1}$ flow rate. A major reason for using a concentration of $1 \%$ was to achieve maximum sensitivity of PDA detection at low wavelengths. The specificity of the method is illustrated in Fig. 1, which indicates separation of the compounds was complete. Average retention times \pm standard deviation for IS, GLIMP, MET and PIO were 3.165 $\pm 0.027,0.425 \pm 0.005$ and $2.3 \pm 0.025 \mathrm{~min}$, respectively, for six replicate analyses. In determination of accuracy and precision, recovery was $99.95 \pm 2 \%$, which indicates the method is accurate, and intra-day and inter-day variation, as RSD, were no more than $0.482 \%$, indicating the method is precise. In determination of the robustness of the method, slight variation of mobile phase $\mathrm{pH}$, amount of buffer, in the mobile phase, and detector wavelength had no significant effect on chromatographic resolution.

Mass spectrometry parameters to develop and validate a selective and rapid assay method for simultaneously determination of glimepiride, metformin and pioglitazone in pharmaceutical dosage form. MS parameters were optimized by infusing standard analyte solution of $500 \mathrm{ng} \mathrm{mL}^{-1}$ into the mass spectrometer having atmospheric pressure electrospray as the ionization source. The signal intensities obtained in ion mode for glimepiride, metformin and pioglitazone was found to be much higher positive ion mode $(\mathrm{M}+)$ - parent ion at $\mathrm{m} / \mathrm{z}, 491.11,129.87$ and 357.04 and tolazamide (internal standard) were higher in positive ion mode $(\mathrm{M}+\mathrm{H})+$ parent ions at $\mathrm{m} / \mathrm{z} 312.04$, respectively in QUATTROZQ full scan mass spectra. Fragmentation was initiated using sufficient nitrogen for collision-activated dissociation and by applying $8 \mathrm{~V}$ collision energy to break the parent ions. It was observed that higher nebuliser gas pressure (70 psi) had a better impact on spectral response. The intensity was further enhanced after acidifying the solution, as it increases the ionization (protonation) resulting in high response in positive ion mode. Cone voltage, capillary voltage Source temperature and desolvation gas temperature did not have much impact on behavior of compounds and were maintained at 3.50, $30.00,120^{\circ} \mathrm{C}$ and $350{ }^{\circ} \mathrm{C}$, respectively. There was no cross talk between the MRMs of analytes and IS. Fine tuning of gas 1 (nebuliser gas), gas 2 (heater gas) and CAD gas was done to get a consistent and stable response with high signal to noise ratio. Figs. 1-3 show the mass spectra of parent and product ions for analytes and IS, respectively. An APEI single probe was selected as the ionization source as it gave high spectral response for both the analytes and the regression curves obtained were linear. The APEI source provided reliable data on method validation and for quantitation of drugs in pharmaceutical dosage form. Since glimepiride, metformin, pioglitazone and tolazamide have different physicochemical properties, it was difficult to set chromatographic conditions that produced sharp peak shape and adequate response. This included mobile phase selection, flow rate, column type and injection volume. Acetonitrile and methanol were tried in different ratio with buffers like ammonium acetate, ammonium formate as well as acid additive like acetic acid in varying strength. It was observed that $1 \%$ ammonium acetate ( $\mathrm{pH} 2.5$ with trifluoro acetic acid): acetonitrile as the mobile phase in gradient mode was most appropriate to give best sensitivity, efficiency and peak shape. Acidic buffer helped to improve the peak shape and spectral response. 50\% aqueous part was adequate to retain the polar compound glimepiride, metformin and pioglitazone. The use of a short chromatography column Waters ACQUITY HSS $\mathrm{C} 18,1.8 \mu \mathrm{m}, 2.1 \mathrm{X} 50 \mathrm{~mm}$ helped in the separation and elution of all four compounds including internal in a very short time. The total chromatographic run time was $5 \mathrm{~min}$ for each run. Simultaneous recovery of the 
glimepiride, metformin and pioglitazone were $98.50 \%-99.88 \%, 98.91 \%-99.95 \%$ \& $97.5 \%-99.9 \%$ respectively. Overall, this method is fast and simple in terms of chromatography and sample preparation, respectively, which helped in giving a high turn around for routine sample analysis. The developed method was validated in accordance with ICH guidelines. Since all three drugs viz glimepiride, metformin and pioglitazone and tolazamide (internal standard) had similar chromatographic behavior. Moreover, there was no significant matrix effect of IS on the analytes. Also, the validation results obtained from this UPLC-MS/MS methodology encouraged its selection as an IS for the present study.

\section{Method Validation \\ * System Suitability}

The RSD values of peak area and retention time for drugs and IS are within $2 \%$ indicating the suitability of the system (Table - 2)

\section{* Linearity}

The calibration curves were prepared by plotting the peak areas of the drug to IS which were linear in the range of 2-12 $\mathrm{ng} \mathrm{mL}^{-1}, 500-3000 \mathrm{ng} \mathrm{mL}^{-1}$ and 15-90 $\mathrm{ng} \mathrm{mL}^{-1}$ of GLIMP, MET, and PIO respectively. Peak area ratios and concentrations were subjected to least square linear regression analysis to calculate the calibration equations and correlation coefficients. The mean regression equations were found as $y=0.0066 \mathrm{x} \mathrm{R}^{2}$ $=0.9987(\mathrm{n}=6), \mathrm{y}=0.0014 \mathrm{x}-0.0084 \mathrm{R}^{2}=0.9988(\mathrm{n}=6)$ and $\mathrm{y}=0.0031 \mathrm{x} \mathrm{R} \mathrm{R}^{2}=0.9976(\mathrm{n}=6)$ for GLIMP, MET, and PIO respectively. $y=a x+b$ where " $y$ " is the peak area ratio of drugs, "a" is the slope, "b" is the intercept and " $\mathrm{x}$ " is the concentration of the measured solution in $\mathrm{ng} \mathrm{mL}$ ". The result shows that there is an excellent correlation between the peak area ratios and the concentrations of drugs in the range tested.

\section{* LOD and $L O Q$}

The LOD was $0.5 \mathrm{ng} \mathrm{mL}^{-1}$ for GLIMP, $1.0 \mathrm{ng} \mathrm{mL}^{-1}$ for MET and $1.0 \mathrm{ng} \mathrm{mL}^{-1}$ for PIO at a signal to noise ratio of 3.3. The limit of quantification was determined as $1 \mathrm{ng} \mathrm{mL}^{-1}$ for GLIMP, $5 \mathrm{ng} \mathrm{mL} \mathrm{MET}^{-1}$, and 5 $\mathrm{ng} \mathrm{mL} \mathrm{m}^{-1}$ for PIO at a signal to noise ratio of 10 .

\section{* Precision}

Intra-day precision was performed by relative standard deviation of six repeated assays of samples at the three concentration levels. Inter-day precision was determined by analyzing the same set of samples of five different days. The RSD values were found to be 1.106-1.922\% for GLIMP, 0.013-0.043\% for MET and 0.083$0.712 \%$ for PIO respectively, indicating good precision (Table - 2).

\section{* Recovery}

To examine the accuracy of the method, recovery studies were carried out by standard addition method. The percent recovery of the added standard to the assay samples was calculated from:

$$
\text { Recovery } \%=\left[\left(\mathrm{C}_{1}-\mathrm{C}_{\mathrm{u}}\right) / \mathrm{C}_{\mathrm{a}}\right] \times 100
$$

Were $C_{1}$ is the total concentration of analyte found; $C_{u}$ is the concentration analyte present in the formulation; and $\mathrm{C}_{\mathrm{a}}$ is the concentration added to the formulation. The average percent recoveries recoveries obtained as $98.95-99.87 \%$ indicate good accuracy of the method (Table- 3)

\section{* Specificity}

The specificity of the UPLCMS method was determined by the complete separation of GLIMP, MET, and PIO and IS as show in (Figure: 1$)$ with parameters like retention time $\left(t_{R}\right)$, resolution $\left(R_{s}\right)$ and tailing factor (T). The peaks obtained for GLIMP, MET, and PIO and IS were sharp and have a clear baseline separation.

\section{* Robustness}

To ensure the insensitivity of the HPLC method to minor changes in the experimental conditions it is important to demonstrate robustness of the method. None of the modifications caused a significant change in the resolution between the drugs and IS, peak area RSD, USP tailing factor, peak width or theoretical plates. 


\section{CONCLUSION}

A simple, rapid, and reliable UPLCMS method has been established for simultaneous determination of GLIMP, MET, and PIO either alone or in their ternary formulations. The method has several advantages, including rapid analysis, a simple mobile phase, simple sample preparation, and improved sensitivity. It is suitable for analysis of these antidiabetic agents in their ternary formulations in a single isocratic run, in contrast with previous methods. This makes the method suitable for routine analysis in quality-control laboratories.

\section{Acknowledgement}

The authors would like to thank JSS University Mysore, India, JSS College of Pharmacy Mysore, Karnataka, India for providing all facilities to complete this research work.

\section{REFERENCES}

[1.] Cheng, J.T., Huang, C.C., Liu, I.M., et al., Novel mechanism for plasma glucose lowering action of metformin in streptozotocin-induced diabetic rats Diabetes, 2006: 55; 819-825.

[2.] Lebovitz H.E., Oral antidiabetic agents, Medical Clinical North America, 2004: 88; 847-863.

[3.] David Bell S.H., Type 2 diabetes mellitus: what is the optimal treatment regimen, The American Journal of Medicine, 2004: 116(5); 23-29.

[4.] Pandit V., Gorantla R., Devi K., et al. Preparation and characterization of pioglitazone cyclodextrin inclusion complexes. J. Young Pharm. 2011: 3; 267-274.

[5.] Bell D. S., Ovalle F., Long-term efficacy of triple oral therapy for type 2 diabetes mellitus. Endocr. Pract. 2002; 8: 271-275.

[6.] Burke J., Combination treatment with insulin and oral agents in type 2 diabetes mellitus. Br. J. Diabetes Vasc. Dis., 2004; 4:71-76.

[7.] Bailey C. J, Turner R. C., Metformin, New England Journal of Medicine, 1996: 334; 574-579.

[8.] Hofmann C.A., Edwards C.W., Colca J.R., et al., Treatment of insulin-resistant mice with the oral antidiabetic agent pioglitazone: evaluation of liver GLUT2 and phosphoenolpyruvate carboxykinase expression, Endocrinology, 1992: $130(1) ; 735-740$.

[9.] Waugh J., Keating G. M., Plosker G. L., Pioglitazone: A Review of its Use in Type 2 Diabetes Mellitus Drugs, 2006; 66: 85109.

[10.] Derosa G., Salvadeo S. A., Glimepiride-pioglitazone Hydrochloride in the Treatment of Type 2 Diabetes. Clinical Med Ther., 2009: 1; 835-845.

[11.] Kletzien R. F., Foellmi L. A., Harris P. K., et al., Adipocyte fatty acid-binding protein: regulation of gene expression in vivo and in vitro by an insulin-sensitizing agent, Molecular Pharmacology, 1992: 42(4); 558-562.

[12.] Vijaya Kumari K., Nageswara Rao P., et al., Simultaneous determination of pioglitazone and candesartan in human plasma by LC-MS/MS and its application to a human pharmacokinetic study, Journal of Pharmaceutical Analysis 2012; 2(3): 167173.

[13.] Xue Y.J., Turner K.C., Pursley J., et al., Quantitative determination of pioglitazone in human serum by direct injection high performance liquid chromatography mass spectrometry and its application to a bioequivalence study, Journal of Chromatography B, 2003; 795: 215-226.

[14.] Lin Z.J., Ji W., Desai Krieger D., et al., Simultaneous determination of pioglitazone and its two active metabolites in human plasma by LC-/MS/MS, Journal of Pharmaceutical and Biomedical Analysis, 2003; 33: 101-108.

[15.] Sengupta P., Sarkar A.K., Bhaumik U., et al., Development and validation of an LC-ESI-MS/MS method for simultaneous quantitation of olmesartan and pioglitazone in rat plasma and its pharmacokinetic application, Biomed. Chromatogr. 2010; 24: 1342-1349.

[16.] Meshram D. M., Langade D. G., et al. Evaluation of efficacy and safety of fixed dose combination of glimepiride 2 mg pluspioglitazone $15 \mathrm{mg}$ plus metformin SR $500 \mathrm{mg}$ in the management of patients with type-2 diabetes mellitus. J. Indian Med Assoc. 2005; 103: 447-450.

[17.] Kishore Kumar H., Narasimha Reddy Y., et al., Simultaneous Determination of Atorvastatin and Glimepiride by LCMS/MS in Human Plasma and Its Application to a Pharmacokinetic Study, American Journal of Analytical Chemistry, 2012; 3: 559-569.

[18.] Zhong G., Bi H., Zhou S., et al., Simultaneous determination of metformin and gliclazide in human plasma by liquid chromatography-tandem mass spectrometry: application to a bioequivalence study of two formulations in healthy volunteers, Journal of Mass Spectrom. 2005; 40: 1462-1471.

[19.] Abu Ruz S., Millership J., McElnay J., The development and validation of liquid chromatography method for the simultaneous determination of metformin and glipizide, gliclazide, glibenclamide or glimperide in plasma, Journal of Chromatography B, 2005; 817: 277-286.

[20.] Karra V.K., Pilli N.R., Inamadugu J.K., et al., Simultaneous determination of pioglitazone and candesartan in human plasma by LC-MS/MS and its application to a human pharmacokinetic study, Journal of Pharmaceutical Analysis, 2012; 2: 167-173.

[21.] Sengupta P., Bhaumik U., Ghosh A., Sarkar A. K., et al., LC-MS-MS Development and Validation for Simultaneous Quantitation of Metformin, Glimepiride and Pioglitazone in Human Plasma and Its Application to a Bioequivalence Study, Chromatographia, 2009; 69(1): 1243-1250. 
UPLCMS Method Development and Validation of Tablet Dosage form Containing Glimepride, Metformine and...

Table - 1. Results of system suitability study

\begin{tabular}{|c|c|c|c|c|c|c|c|c|}
\hline & \multicolumn{2}{|c|}{ Glimepiride } & \multicolumn{2}{|c|}{ Metformin } & \multicolumn{2}{|c|}{ Pioglitazone } & \multicolumn{2}{|c|}{ Tolazamide (IS) } \\
\hline & $\begin{array}{l}\text { Retention time } \\
(\mathrm{min})\end{array}$ & Peak area & $\begin{array}{l}\text { Retention time } \\
(\min )\end{array}$ & Peak area & $\begin{array}{l}\text { Retention time } \\
(\min )\end{array}$ & Peak area & $\begin{array}{l}\text { Retention time } \\
(\min )\end{array}$ & Peak area \\
\hline Mean & 3.17 & 2439 & 0.425 & 133977 & 2.3 & 1823 & 2.8 & 63575 \\
\hline SD & 0.027 & 17.352 & 0.005 & 1920.70 & 0.025 & 18.76 & 0.009 & 374.278 \\
\hline RSD & 0.865 & 0.712 & 1.289 & 1.434 & 1.073 & 1.029 & 0.321 & 0.589 \\
\hline
\end{tabular}

Table - 2. Intra-day and inter-day precision and accuracy of GLIMP, MET and PIO

\begin{tabular}{|c|c|c|c|c|c|c|c|}
\hline \multirow[b]{2}{*}{$\begin{array}{l}\text { Name of } \\
\text { the drug }\end{array}$} & \multirow[b]{2}{*}{$\begin{array}{c}\text { Actual } \\
\text { concentration } \\
\left(\mathbf{n g ~ m L} \mathbf{~ m L}^{-1}\right)\end{array}$} & \multicolumn{3}{|c|}{ Intra-day } & \multicolumn{3}{|c|}{ Inter-day } \\
\hline & & $\begin{array}{c}\text { Found } \\
\text { concentration } \\
\left.\mathrm{mL}^{-1}\right) \pm \mathrm{SD}\end{array}$ & $\begin{array}{c}\text { RSD } \\
(\%)\end{array}$ & $\begin{array}{l}\text { RME } \\
(\%)\end{array}$ & $\begin{array}{l}\text { Found concentration } \\
\qquad\left(\mathrm{ng} \mathrm{mL} \mathbf{~ m}^{-1}\right) \pm \mathrm{SD}\end{array}$ & $\begin{array}{r}\text { RSD } \\
(\%)\end{array}$ & $\begin{array}{l}\text { RME } \\
(\%)\end{array}$ \\
\hline \multirow[t]{2}{*}{ GLIMP } & 8 & $7.723 \pm 0.147$ & 1.913 & 0.855 & $7.753 \pm 0.148$ & 1.912 & 0.855 \\
\hline & 10 & $9.898 \pm 0.109$ & 1.106 & 0.495 & $9.768 \pm 0.146$ & 1.495 & 0.669 \\
\hline \multirow{2}{*}{ MET } & 1500 & $1499.760 \pm 0.202$ & 0.013 & 0.006 & $1499.323 \pm 0.648$ & 0.043 & 0.019 \\
\hline & 2500 & $2499.338 \pm 0.701$ & 0.028 & 0.013 & $2499.135 \pm 0.727$ & 0.029 & 0.013 \\
\hline \multirow{3}{*}{ PIO } & 45 & $44.835 \pm 0.129$ & 0.287 & 0.128 & $44.703 \pm 0.224$ & 0.502 & 0.224 \\
\hline & 60 & $59.890 \pm 0.079$ & 0.131 & 0.059 & $59.550 \pm 0.424$ & 0.712 & 0.319 \\
\hline & 75 & $74.815 \pm 0.062$ & 0.083 & 0.037 & $74.607 \pm 0.467$ & 0.626 & 0.280 \\
\hline
\end{tabular}

Table - 3. Results of recovery studies by standard addition method

\begin{tabular}{|c|c|c|c|c|c|}
\hline $\begin{array}{c}\text { Name of the } \\
\text { drug }\end{array}$ & $\begin{array}{c}\text { Amount of } \\
\text { drug in tablet } \\
(\mathbf{n g})^{\mathbf{a}}\end{array}$ & $\begin{array}{c}\text { Amount of } \\
\text { pure drug } \\
\text { added (ng) }\end{array}$ & $\begin{array}{c}\text { Total found (ng) } \\
\text { (Mean+SD) }\end{array}$ & RSD (\%) & $\begin{array}{c}\text { Recovery of } \\
\text { pure drug } \\
\text { added (\%) }\end{array}$ \\
\hline \multirow{3}{*}{ GLIMP } & 5.24 & 4 & $9.198 \pm 0.044$ & 0.483 & 98.95 \\
\cline { 2 - 6 } & 5.24 & 6 & $11.19 \pm 0.042$ & 0.377 & 99.23 \\
\cline { 2 - 6 } & 5.24 & 8 & $13.18 \pm 0.051$ & 0.391 & 99.25 \\
\hline \multirow{3}{*}{ MET } & 1497.62 & 1000 & $2496.29 \pm 0.958$ & 0.038 & 99.87 \\
\cline { 2 - 6 } & 1497.62 & 1500 & $2992.28 \pm 6.866$ & 0.229 & 99.60 \\
\hline \multirow{3}{*}{ PIO } & 1497.62 & 2000 & $3483.72 \pm 12.779$ & 0.367 & 99.30 \\
\cline { 2 - 6 } & 44.85 & 30 & $74.558 \pm 0.279$ & 0.374 & 99.0 \\
\cline { 2 - 6 } & 44.85 & 45 & $89.49 \pm 0.431$ & 0.482 & 99.20 \\
\hline
\end{tabular}

Table - 4.

\begin{tabular}{|c|c|c|c|c|}
\hline $\begin{array}{c}\text { Name of the } \\
\text { drug }\end{array}$ & $\begin{array}{l}\text { Linearity } \\
\text { range } \\
\left.(\mathrm{ng} \mathrm{mL})^{-1}\right)\end{array}$ & $\begin{array}{c}\text { LOD } \\
\left(\mathbf{n g ~ m L} \mathbf{~}^{-1}\right)\end{array}$ & $\begin{array}{c}\text { LOQ } \\
\left(\mathrm{ng} \mathrm{mL}^{-1}\right)\end{array}$ & Regression equation \\
\hline GLIMP & $2-12$ & 0.5 & 1.0 & $y=0.0066 x R^{2}=0.9987(n=6)$ \\
\hline MET & $500-3000$ & 1.0 & 4.0 & $y=0.0014 x-0.0084 R^{2}=0.9988(n=6)$ \\
\hline PIO & $15-90$ & 1.0 & 5.0 & $y=0.0031 x R^{2}=0.9976(n=6)$ \\
\hline
\end{tabular}


${ }^{a}$ Geoglit GM 20 tablets purchased from a local drug store (containing 2 mg GLIMP, 500 mg MET 15 mg PIO)

${ }^{\mathrm{b}}$ Five independent analyses

${ }^{c}$ Standard deviation

\section{UPLC Chromatograms}

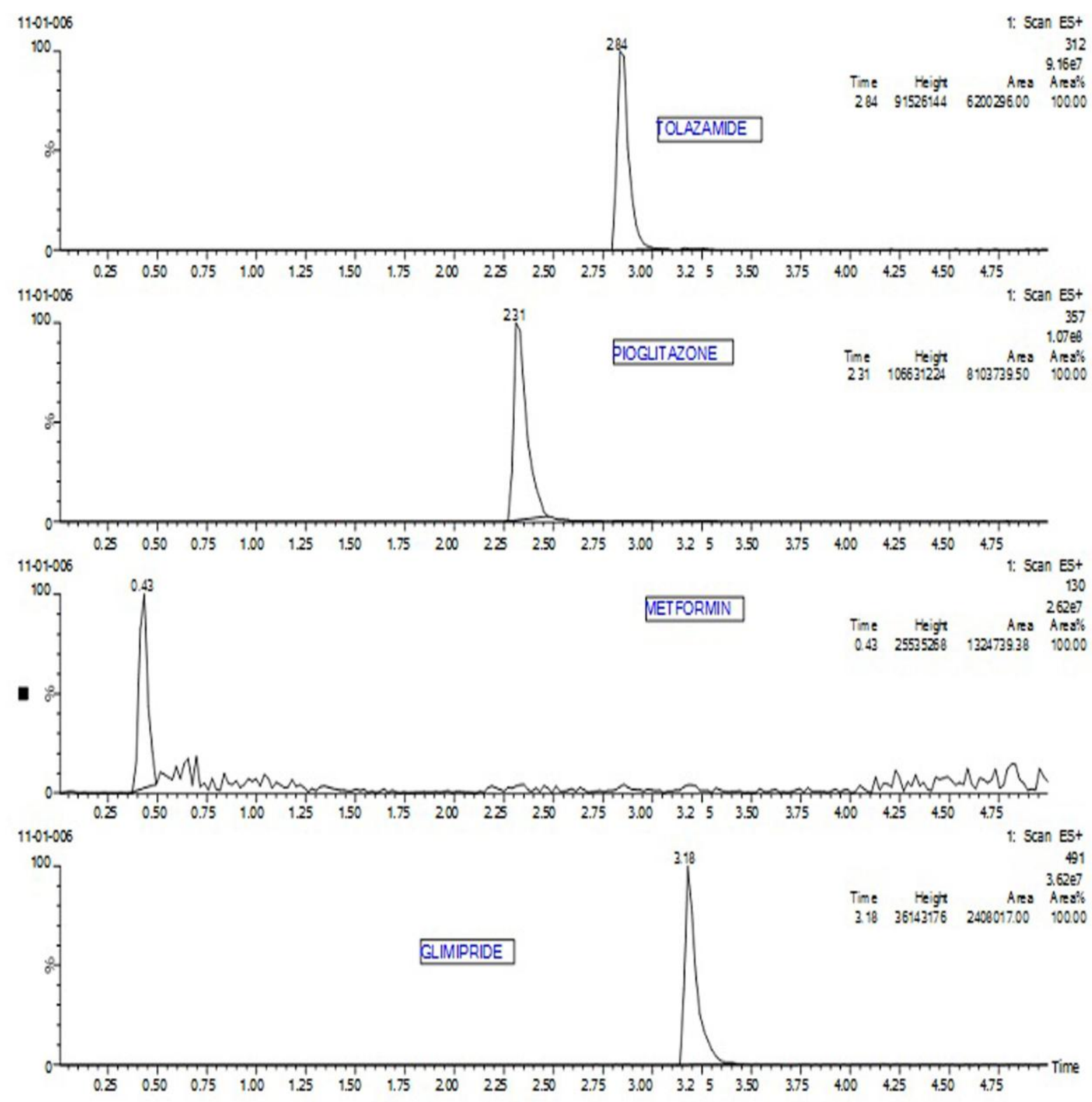

Figure: 1 


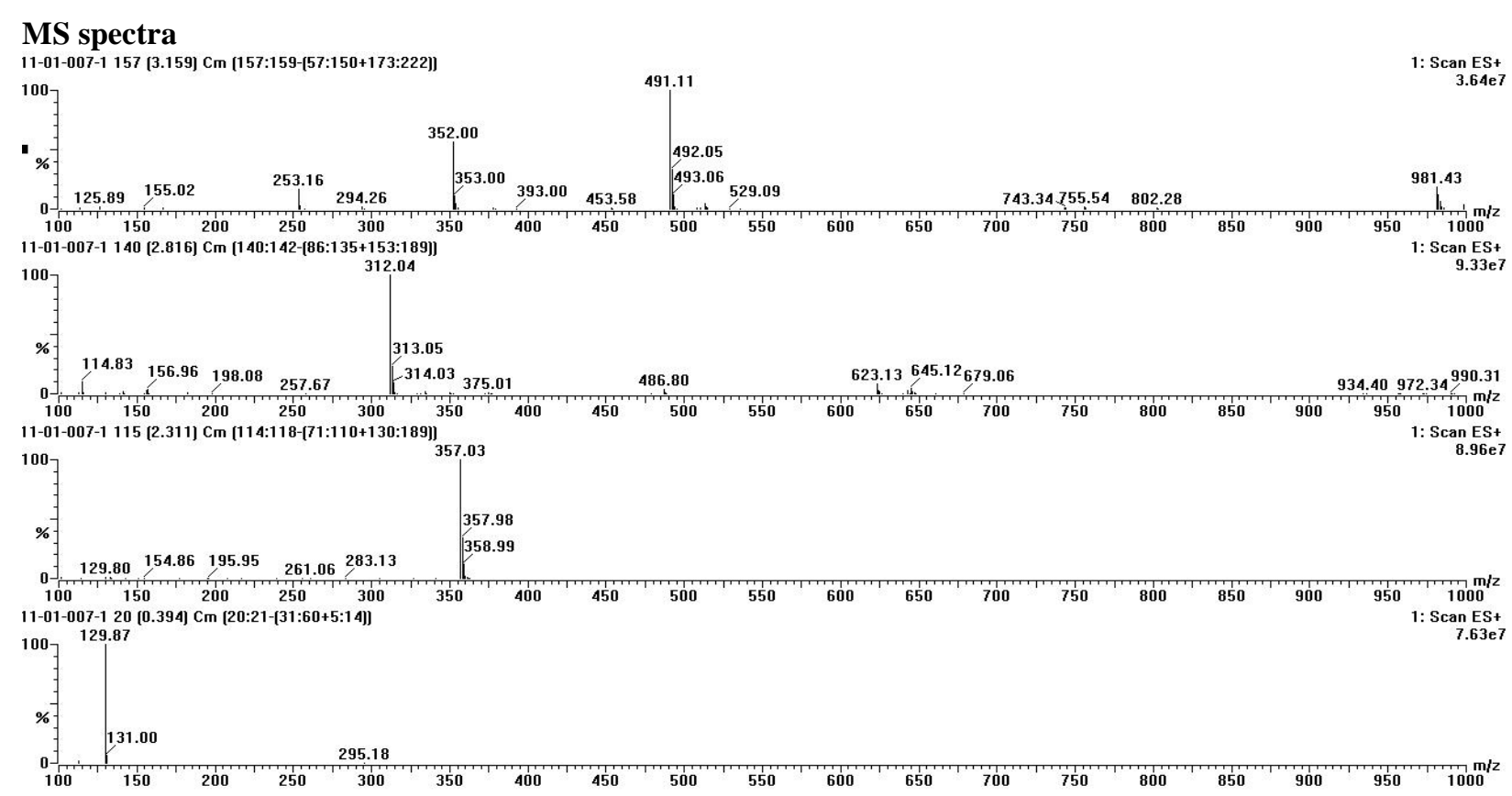

\section{Blank}

Figure: 2

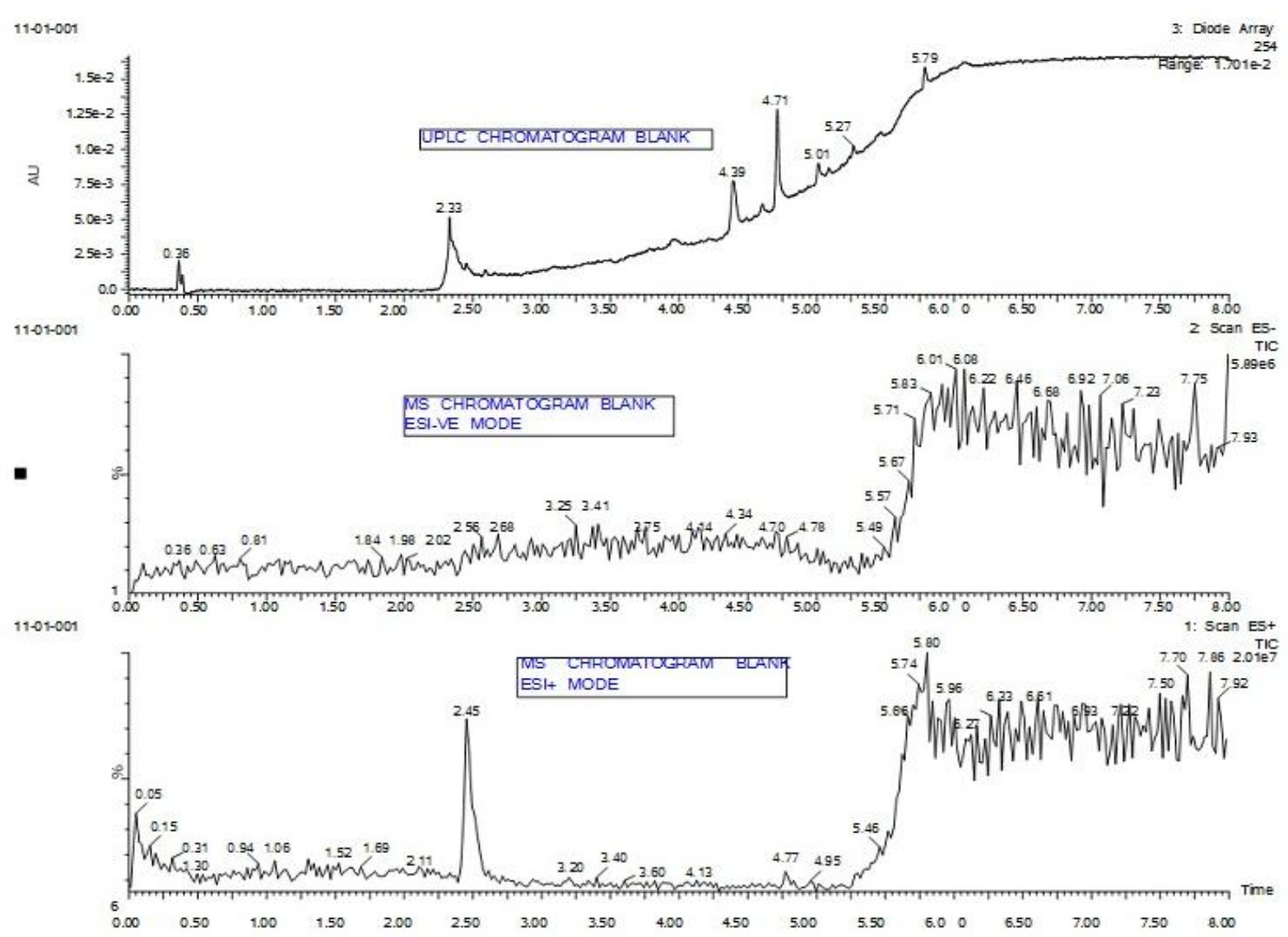

Figure: 3 